\title{
Etkileşimli parçacık hidrodinamiği kullanılarak trapez eşik üzerinden geçen baraj yıkılması akımının sayısal olarak modellenmesi
}

\section{Numerical modeling of dam-break flow over trapezoidal obstacle using smoothed particle hydrodynamics}

\author{
Selahattin Kocaman 1,* \\ ${ }^{1}$ İskenderun Teknik Üniversitesi, İnşaat Mühendisliği Bölümü, 31200, Hatay Türkiye.
}

\section{Özet}

Bir baraj yıkılması olayı gerçekleştiğinde, yüksek miktardaki su kütlesi ani bir șekilde mansap kısmına doğru yayılmaya bașlar ve mansap bölgesinin topografyası, baraj yıkılmasi akımının ana karakteristikleri üzerinde önemli etkilere sahiptir. Etki alanı içerisinde olası afetlerin önlenmesi için baraj yıkılması akımlarının dalga yayılma hızı ve su yüksekliği gibi temel özelliklerinin belirlenmesi büyük önem taşımaktadır. Bu tür akımların saha verilerinin elde edilmesindeki zorluklar, bu alanda yapılan deneysel ve nümerik çalışmaların önemini arttırmaktadır. Sunulan çalışmada mansap kesitinde trapez bir esik bulanan baraj yıkılması akımının Etkileşimli Parçacık Hidrodinamiği (EPH) yöntemi ile nümerik analizi gerçekleştirilmiştir. EPH yönteminin çözüm kabiliyeti, üç farkl parçacık çözünürlüğünden elde edilen analiz sonuçlarının deneysel ölçümlerle karşılaştırılmasıyla test edilmiştir. Genel olarak deneysel ölçüm verileri ile nümerik hesaplamalar arasında iyi bir uyum gözlemlenmiş ve parçacı çözünürlüğünün sonuçlar üzerindeki etkisi tartışılmıştır.

Anahtar kelimeler: Baraj yıkılması, Etkileşimli parçacık hidrodinamiği, Sayısal model, Trapez eşik.

\section{Giris}

Bir baraj yıkılması olayı gerçekleştiğinde, oluşan taşkın dalgaları ani bir şekilde mansap kısmına doğru yayılmaya başlar ve etki alanı içerisinde önemli ölçüde can ve mal kayıplarına neden olabilir. Taşkın dalgalarının yayıldığı mansap kısmı genellikle doğal veya insan yapımı engellerin neden olduğu topoğrafik düzensizlikler barındırmaktadır. Taşkın dalgasının yayılımı üzerinde belirgin etkileri olan bu düzensizlikler, akımı incelemek ve noktasal derinlik, dalga yayılım hızı gibi ana karakteristiklerini belirlemek için yapılan çalışmaları daha karmaşık hale getirmektedir.

İlgili saha verilerinin elde edilmesindeki zorluk, araştırmacıları bu alanda deneysel çalışmalar yapamaya yönlendirmiştir. Birçok araştırmacı, mansap kısmındaki çeşitli geometrilerde engellerin ve daralmaların oluşturduğu düzensizliklerin etkilerini deneysel çalışmalar gerçekleştirerek incelemeyi amaçlamışlardır [1-6]. Elde edilen deneysel verilerin analitik metotlar ile yeteri doğrulukta yeniden üretilememesi ise bu alanda kullanılan nümerik yöntemlerin değerini ve önemini arttırmaktadır. Nümerik yöntemler son yıllarda hidrolik problemlerinin çözümünde sıklıkla kullanılmaktadır [7, 8]. Literatürde baraj yıkılması akımlarının analizinde kullanılmak üzere birçok nümerik metot geliştirilmiş ve araştırmacılar tarafından başarı ile uygulanmıştır. Bu metotları genel olarak ağ ve

\begin{abstract}
When a dam-break phenomenon occurs, the large amount of water rapidly starts to propagate towards the downstream and, the topography of the downstream has significant effects on the main characteristics of the dambreak flow. It has great importance to determine the main characteristics of the dam-break flows such as wave propagation velocity and water height in order to prevent possible disasters which can cause destructive effects in the impact area. Difficulties in obtaining field data of this type of flows increase the importance of experimental and numerical studies in this field. In the presented study, the numerical analysis of the dam-break flow with a trapezoidal hump in the downstream was performed by the Smoothed Particle Hydrodynamics (SPH) method. The solution capability of the SPH method was tested by the comparisons of the analysis results obtained from three different particle resolution with experimental measurements. In general, a good agreement was observed between experimental measurement data and numerical calculations and, the effect of particle resolution on the results was discussed.
\end{abstract}

Keywords: Dam-break, Smoothed particle hydrodynamics, Numerical model, Experiment, Trapezoidal obstacle.

parçacık tabanlı metotlar olmak üzere iki gruba ayırmak mümkündür. Ağ tabanlı nümerik metotlar birçok araştırmacı tarafından çeşitli baraj yıkılması akımlarının incelenmesinde s1klıkla başvurulan yöntemler olmuşlardır [2-5, 9-12]. Bu metotlar ile gayet başarılı sonuçlar elde edilebilirken, kullanılan formülasyona bağlı olarak serbest yüzeyin tespiti için ilave denklemler gerektirmeleri, ağ yapısının düzenlenme şekline hassasiyetleri ve çözüm süresi ile ilgili zamansal maliyetleri metotların olumsuz yanları olarak göze çarpmaktadır.

Son yıllarda parçacık tabanlı metotlar ise birçok araştırmacı tarafından serbest yüzeyli akımların nümerik olarak modellenmesinde ilk tercih edilen metotlar haline gelmişlerdir. $\mathrm{Bu}$ metotların herhangi bir ağ yapısı barındırmaması ve serbest yüzey evriminin tespiti için ilave denklemlere ihtiyaç duyulmaması gibi öne çıkaran özellikleri bulunmaktadır. $\mathrm{Bu}$ yöntemlerin en popülerlerinden biri olan Etkileşimli Parçacık Hidrodinamiği (Smooted Particle Hydrodynamics) metodu ilk olarak astrofizik problemlerine uygulanmak üzere geliştirilmişse de [13, 14] daha sonraları birçok hidrodinamik problemine başarı ile uygulanmıştır [15-18]. Hidrodinamik problemlerde kullanımı açısından ağ yapılı metotlara göre nispeten daha yeni olan bu yöntemin

\footnotetext{
* Sorumlu yazar / Corresponding author, e-posta / e-mail: selahattin.kocaman@iste.edu.tr (S. Kocaman) Geliş / Recieved: 13.10.2020 Kabul/ Accepted: 12.11.2020 Yayımlanma / Published: 15.01.2021 doi: $10.28948 /$ ngmuh.810306
} 
kullanılan parametrelere olan duyarlılığ 1 ise araştırmacılar arasında popüler bir araştırma konusu olmaktadır.

$\mathrm{Bu}$ çalışmada, mansap bölgesinde trapez geometrili bir eşik bulunan baraj yıkılması akımının Etkileşimli Parçacık Hidrodinamiği (EPH) metodu ile nümerik analizi gerçekleştirilmiştir. Parçacık çözünürlüğünün sonuçlar üzerindeki etkisinin test edilmesi amacı ile analizler üç farklı çözünürlük değeri için tekrarlanmıştır. Elde edilen nümerik çözüm sonuçları, Kocaman [19] tarafindan gerçekleştirilen deneysel çalışma sonucu elde edilen çeşitli noktalardaki boyutsuz su derinliği değerlerinin zamana göre değişimleri üzerinden karşılaştırılmıştır.

\section{Etkileşimli parçacık hidrodinamiği metodu}

$\mathrm{Bu}$ çalışmadaki sayısal analizler, açık kaynak kodlu, Grafik İşlemci Birimi (GPU) ve Merkezi İşlem Birimi (CPU) üzerinden işlem gerçekleştirebilen, EPH çözücüsü DualSPHysics [20] kullanılarak gerçekleştirilmiştir. EPH yönteminde sürekli akışkan ortamı, oluşturulan parçacık setleri ile tanımlanmaktadır. Temel olarak bir interpolasyon teorisi olan yöntemde, hidrodinamiğin temel korunum yasaları bir çekirdek fonksiyonu yardımıyla ifade edilebilmektedir;

$$
A(\boldsymbol{r})=\int A\left(\boldsymbol{r}^{\prime}\right) W\left(\boldsymbol{r}-\boldsymbol{r}^{\prime}, h\right) d \boldsymbol{r}^{\prime}
$$

Burada A(r) konuma bağlı bir fiziksel özelliği temsil ederken, W(r-r',h) ağırlık fonksiyonudur. A ğırlık fonksiyonu ile interpolasyon uzunluğu (h) içerisindeki parçacıkların katkı oranları belirlenmektedir. Denklem 1, herhangi bir a parçacığı için çekirdek fonksiyonu tarafından belirlenen sınır içerisindeki komşu parçacıklar (b) kullanılarak aşağıdaki şekilde yaklaşık olarak ayrıklaştırılabilmektedir;

$$
A\left(\boldsymbol{r}_{\boldsymbol{a}}\right) \approx \sum_{b} A\left(\boldsymbol{r}_{\boldsymbol{b}}\right) \frac{m_{b}}{\rho_{b}} W\left(r_{a}-r_{b}, h\right)
$$

EPH analizlerinin çözüm kabiliyetleri kullanılan çekirdek fonksiyonuna yüksek oranda bağlılık göstermektedir. Bu çalışmada çekirdek fonksiyonu olarak Wendland [21] tarafından önerilen Quintic (Wendland) tipi bir fonksiyon kullanılmıştır;

$$
\begin{aligned}
W(r, h)= & a_{D}\left(1-\frac{q}{2}\right)^{4}(2 q+1) \\
& 0 \leq q \leq 2
\end{aligned}
$$

burada $\mathrm{r}$; ilgili parçacıklar a ile $\mathrm{b}$ arasındaki mesafeyi temsil ederken, $a_{D}$; iki ve üç boyutlu problemler için sırasıyla $7 / 4 \pi \mathrm{h}^{2}$ ve $21 / 16 \pi \mathrm{h}^{3}$ değerlerini almaktadır.

Serbest yüzeyli baraj yıkılması akımlarının EPH yöntemi ile analizlinde kullanılan temel denklemler momentum ve kütlenin korunumu yasalarıdır. Momentumun korunumu EPH yönteminde;

$$
\frac{d v_{a}}{d t}=-\sum_{b} m_{b}\left(\frac{P_{b}+P_{a}}{\rho_{b} \rho_{a}}+\Pi_{a b}\right) \nabla_{a} W_{a b}+g
$$

şeklinde ifade edilmektedir. Burada P ve $\rho$ sırasıyla basınç ve yoğunluk terimlerini temsil ederken, $g$ yerçekimsel ivme, $\Pi_{\mathrm{ab}}$ ise yapay viskozite terimidir. Bu viskozite terimi;

$$
\Pi_{a b}= \begin{cases}\frac{-\alpha \overline{c_{a b}} \mu_{a b}}{\overline{\rho_{a b}}} & \boldsymbol{v}_{\boldsymbol{a b}} \cdot \boldsymbol{r}_{\boldsymbol{a b}}<0 \\ 0 & \boldsymbol{v}_{\boldsymbol{a b}} \cdot \boldsymbol{r}_{\boldsymbol{a b}}>0\end{cases}
$$

şeklinde ifade edilebilir [22]. Burada $r_{a b}=r_{a}-r_{b}$ ve $v_{a b}=v_{a}-v_{b}$, parçacık pozisyon ve hızlarının farklarını temsil ederken, $\mu_{\mathrm{ab}}=\mathrm{hv}_{\mathrm{ab}} \cdot \mathrm{r}_{\mathrm{ab}} /\left(\mathrm{r}_{\mathrm{ab}}{ }^{2}+\eta^{2}\right) \quad$ ve $\mathrm{c}_{\mathrm{ab}}=0.5\left(\mathrm{c}_{\mathrm{a}}+\mathrm{c}_{\mathrm{b}}\right)$ eşitlikleri söz konusudur. $\eta^{2}=0.01 \mathrm{~h}^{2}$ değerini alırken, $c_{a b}$ ses hızının ortalama değerini temsil etmektedir. $\alpha$ değeri problem tipine bağlı değişiklik gösterebilen yapay viskozite sabitidir.

EPH yönteminde süreklilik denklemi ise;

$$
\frac{d p_{a}}{d t}=\sum_{b} m_{b} \boldsymbol{v}_{a b} \nabla_{a} W_{a b}
$$

şeklinde ifade edilmektedir. DualSPHysics kodu ile gerçekleştirilen EPH analizlerinde akışkanlar, yoğunluğunda \%1 dolaylarında sınırlı dalgalanmalar meydana gelebileceği kabulü ile zayıf sıkıştırılabilir şekilde modellenmektedir. Bu çözüm yaklaşımının kullanımı ile basınç ve yoğunluk arasındaki ilişkiyi tanımlamak üzere bir hal denklemine ihtiyaç duyulmaktadır. Bu doğrultuda bu çalışmada;

$$
P=B\left[\left(\frac{\rho}{\rho_{0}}\right)^{\gamma}-1\right]
$$

hal denklemi kullanılmaktadır [23]. Burada; $\gamma=7$ ve $\mathrm{B}=\mathrm{c}_{0}{ }^{2} \rho_{0} / \gamma$ olup, $\rho_{0}$ suyun referans yoğunluğu ve $\mathrm{c}_{0}$ değeri bu yoğunluktaki bir su içerisindeki ses hızını temsil etmektedir.

\section{Bulgular ve tartışma}

$\mathrm{Bu}$ çalışmada EPH yönteminin bir baraj yıkılması akımının trapez geometrili bir eşik ile olan etkileşiminin sayısal olarak modellenmesindeki performansı Kocaman [19] tarafindan elde edilen deneysel ölçüm verileri kullanılarak test edilmiştir. Deneysel çalışma $8.9 \mathrm{~m}$ uzunluğa, $0.3 \mathrm{~m}$ genişliğe ve $0.34 \mathrm{~m}$ yüksekliğe sahip dikdörtgen bir tank kullanılarak gerçekleştirilmiştir. Dikdörtgen tank, rijit bir kapak kullanılarak memba ve mansap olarak iki kısma ayrılmış, $4.65 \mathrm{~m}$ uzunluğundaki memba kısmı başlangıçta $\mathrm{h}_{0}=0.25 \mathrm{~m}$ derinlikte su ile doldurulmuştur. Rijit kapağın ani bir şekilde kaldırılması ile baraj yıkılması akımının başlangıç su kütlesinden $1.53 \mathrm{~m}$ uzağa konumlandırılmış trapez geometrili bir engelin bulunduğu kuru mansap yatağı üzerinde ilerlemesi sağlanmıştır. Deney düzeneğinin genel görünümü Şekil 1'de gösterilmiştir. Deneysel ölçüm verileri görüntü işleme tekniği ile elde edilmiş olup, bu yöntem ve deney düzeneği hakkında detaylı bilgi Kocaman [19] çalışmasında bulunabilir.

Deneysel veriler ile karşılaştırmak amacıyla $0.00125 \mathrm{~m}$, $0.0025 \mathrm{~m}$ ve $0.005 \mathrm{~m}$ olmak üzere üç farklı parçacıklar arası başlangıç mesafesi (dp) değerine sahip EPH analizi gerçekleştirilmiştir. Analizlerin tümünde Wendland tipi çekirdek fonksiyonu kullanılırken, interpolasyon uzunluğu 
Tablo 1. Nümerik analizlerde kullanılan EPH parametreleri

\begin{tabular}{lcc}
\hline Sayısal Analiz $(\mathrm{SA})$ No & SA1 & SA2 \\
\hline Parçacıklar arası başlangıç mesafesi $(\mathrm{m})$ & 0.005 & 0.0025 \\
Parçacık Sayısı Yoğunluğu $\left(\mathrm{h}_{0} / \mathrm{d}_{\mathrm{p}}\right)$ & 50 & 100 \\
Yapay Viskozite Değeri $(\alpha)$ & & 0.01 \\
$\mathrm{~h} / \mathrm{dp}$ & 1.25 \\
Çekirdek Fonksiyonu & Wendland \\
Sinır şartı formülasyonu & Dynamic Boundary Condition [24] \\
Zaman adımlama tekniği & Symplectic [25] \\
\hline
\end{tabular}

(a)

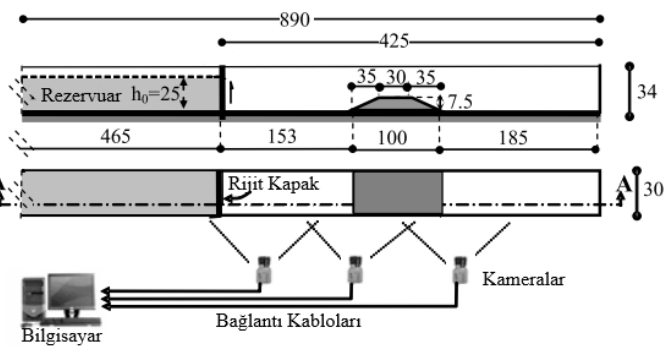

Şekil 1. Deney düzeneğinin önden(a) ve üstten(b) genel görünüşü

(h), her bir analiz için dp değerinin 1.25 katı olacak şekilde seçilmiştir. EPH analizleri ile ilgili detaylı parametrik özet Tablo 1'de sunulmuştur.

$\mathrm{Bu}$ değerler kullanılarak, toplam analiz süresi $12.8 \mathrm{~s}$ olan üç farklı EPH analizi gerçekleştirilmiştir. Deneysel ve sayısal çalışmaya ait çeşitli zaman adımlarındaki karşılaştırmalı görseller Şekil 2'de sunulmuştur.

Rijit kapağın ani bir şekilde kaldırılması ile mansap kısmına doğru yayılmaya başlayan baraj yıkılması dalgasının trapez kesitli eşiğe vardığında bir kısmının eşiği aştı̆̆ bir kısmının ise eşiğin memba tarafinda kalarak kabarmaya başladığı gözlemlenmiştir. Eşiği aşan akımın sel rejiminde olduğu gözlemlenirken, eşik öncesinde kabarma miktarının artması ile $\mathrm{T}=2.80 \mathrm{~s}$ 'de bir hidrolik sıçramanın oluştuğu dikkat çekmektedir. Sonrasında hareketli hidrolik sıçrama olarak tanımlanabilecek bu hidrolik sıçramanın memba doğrultusunda ilerlemesiyle bir negatif dalga meydana gelmektedir. Sayısal sonuçlarda $t=3.30 \mathrm{~s}$ anında deneysel sonuçlardan farklı olarak sıçrama tipi bir dalga kırılması meydana gelmektedir. Ayrıca, hidrolik sıçramanın olduğu (negatif dalga önü) bölgede ve sonrasinda deneysel görsellerde önemli ölçüde hava girişiminden dolayı hava-su arakesiti oluşumları gözlemlenirken, sayısal analiz sonuçlarında kullanılan formülasyonun tek fazlı (su) olması nedeniyle bu durum gözlemlenmemektedir. Deneysel çalışmada hidrolik Dalga kırılması sonucu oluşan negatif dalga önünün baraj membasına doğru ilerlemesi ise analiz süresince devam etmiştir.

Elde edilen nümerik analiz sonuçları ile biri membada ve diğer yedi tanesi mansapta olmak üzere sekiz farklı ölçüm noktasında gerçekleştirilen deneysel ölçümler, boyutsuz su derinliği-zaman grafikleri kullanılarak karşılaştııılmıştır. Kullanılan ölçüm noktalarının dikdörtgen tank içerisindeki konumları Şekil 3'de gösterilmektedir.

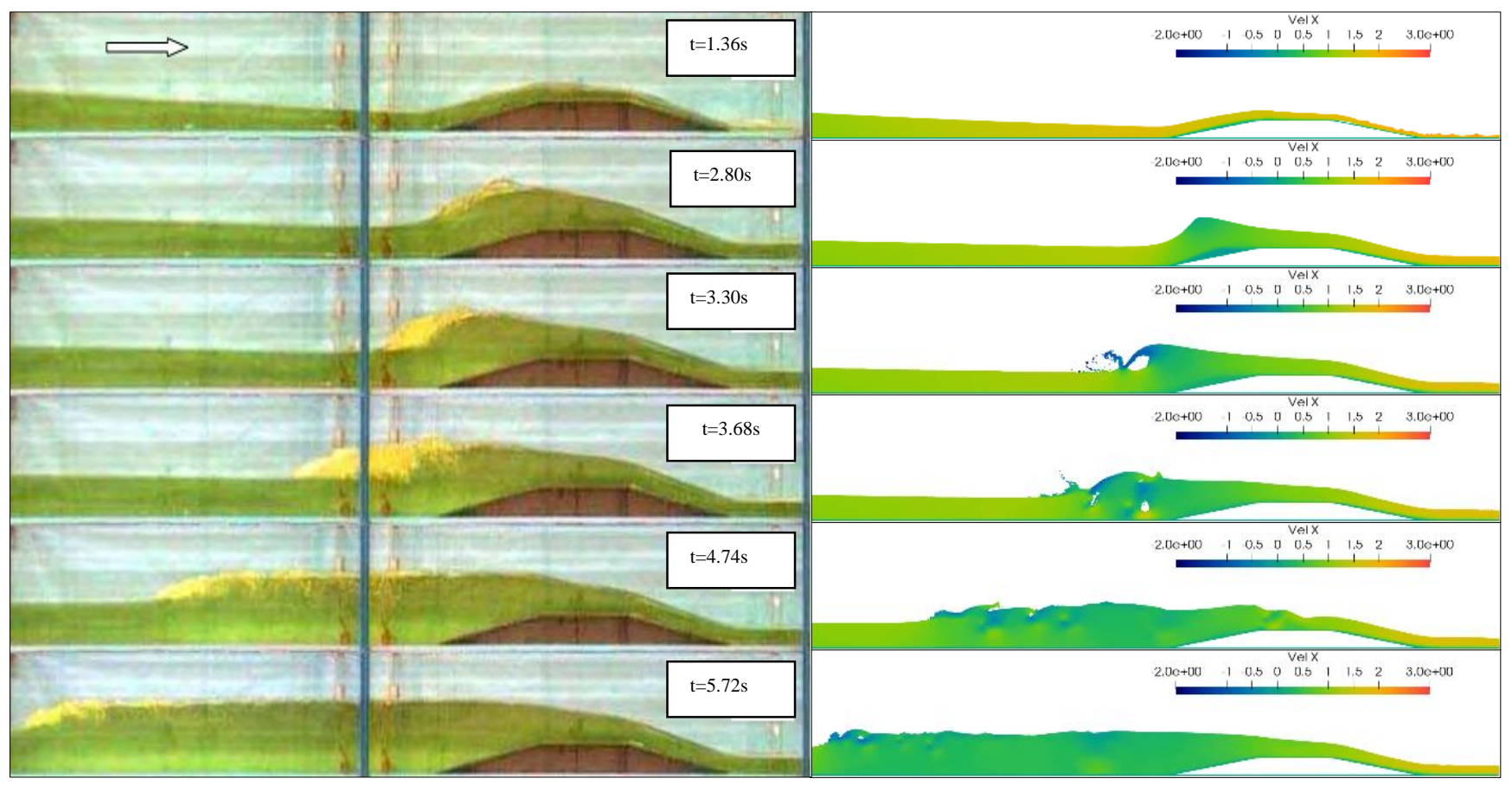

Şekil 2. Çeşitli zaman adımlarına ait deneysel ve sayısal (SA3) görsellerin karşılaştırılması 

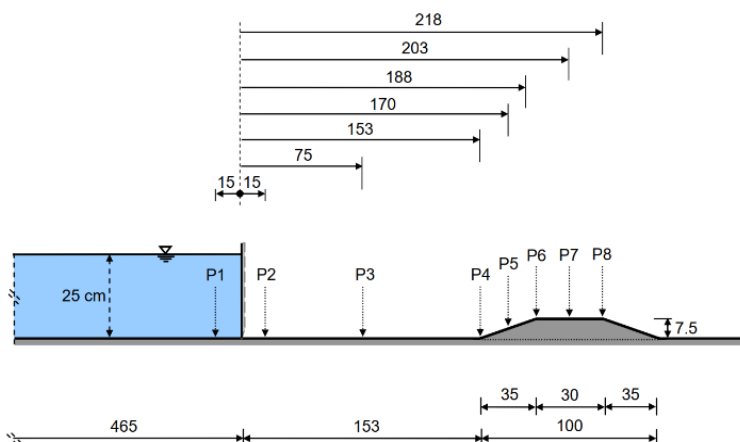

Şekil 3. Su seviyesi ölçüm noktaları

Deneysel ve sayısal analiz sonuçlarının boyutsuz su derinlikleri üzerinden karşılaştııılmaları Şekil 4'de sunulmaktadır. Boyutsuz su derinliği değerleri; mevcut su derinliklerin başlangıç su derinliği değerine $\left(\mathrm{h}_{0}\right)$ bölünmesi sonucu elde edilirken, boyutsuz zaman değerleri; mevcut zaman değerlerinin $\left(\mathrm{g} / \mathrm{h}_{0}\right)^{1 / 2}$ ile çarpılmasılyla elde edilmiştir. Burada $g$ yerçekimi ivmesidir. EPH analizlerinde kullanılan üç farklı çözünürlük değerleri de deneysel ölçümler ile karşılaştırılmıştır. Trapez eşik üzerinde olmayan P1-P4 noktalarında, rijit kapağın aniden kaldırılması ile membada bulunan ve rezervuardaki su seviyesi değişimini temsil eden

P1 noktasında ani bir düşüş, diğer noktalarda ise taşkın dalgasının bu noktalara ulaşması ile ani yükselişler gözlemlenmiştir. Eşik öncesindeki kabarma ve akabindeki negatif dalga yansımasının oluşumuna kadar, bu noktalardaki nümerik model sonuçları arasında kullanılan parçacık çözünürlüğüne bağlı olarak bir farklılaşmanın meydana geldiği gözlemlenmemiş ve deneysel ölçümler ile iyi bir uyum yakalanmıştır. Negatif dalga yansımasının bu noktalardan geçişi sırasında ise sonuçlar arasında farklılıkların başladığı, en düşük çözünürlük değerine sahip analizlerde (SA1) bu dalgaların ölçüm noktalarına daha erken vardığı ve daha yüksek derinliklere ulaştığ gözlemlenmiştir. Ayrıca, çözünürlük değerlerine bağlı olarak negatif dalga önünün geçişinden sonra ölçüm noktalarındaki derinlik değerlerinde düşük çözünürlükten yüksek çözünürlüğe doğru azalan bir derinlik değeri dikkat çekmektedir.

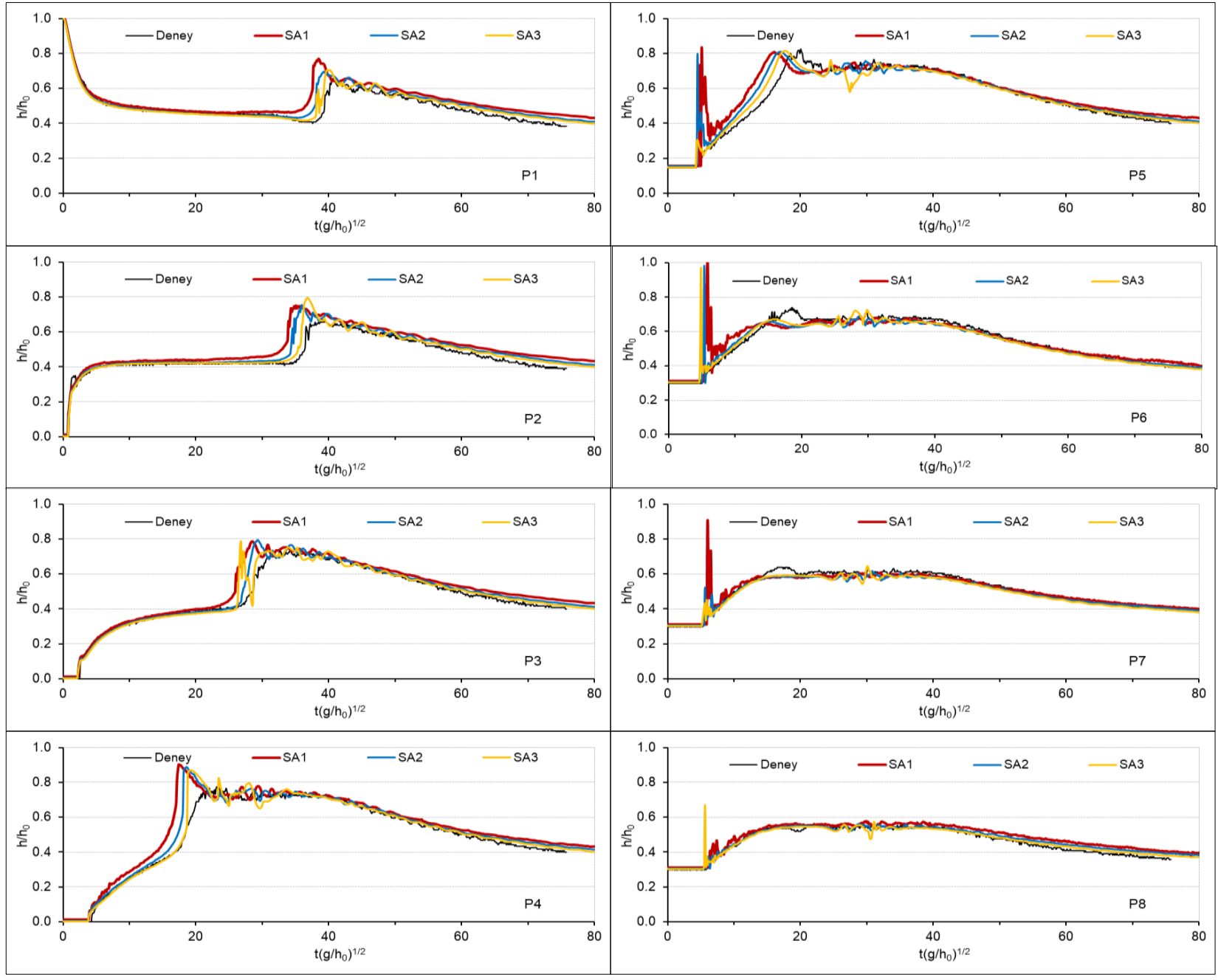

Şekil 4. Nümerik hesaplamaların deneysel ölçüm verileri ile karşılaştırılması 
Tüm bu farklılaşmalar irdelendiğinde yüksek çözünürlük değerlerinin deneysel ölçümler ile daha uyumlu olduğu görülmektedir. Bunun nedeni olarak, ağ tabanlı sayısal metotlarda olduğu gibi, daha fazla sayı ile tanımlanan çözüm alanının, nümerik metotlardaki çözüm yaklaşımları nedeniyle doğruluğu arttırdığı ve akışkanın daha çok parçacık ile daha iyi temsil edilebildiği ileri sürülebilir. Ayrıca, tüm çözünürlük değerlerinde aynı yapay viskozite değerleri kullanılmasına rağmen, yapay viskozite değerinin çözünürlük ile ilişkili olduğu bilinmektedir. Yapay viskozite değerinin problem üstündeki etkisinin arttırılması ile daha fazla enerji yayılımının gerçekleşeceği ve dalga yayılma hızlarında azalmalara neden olacağı düşünülmektedir.

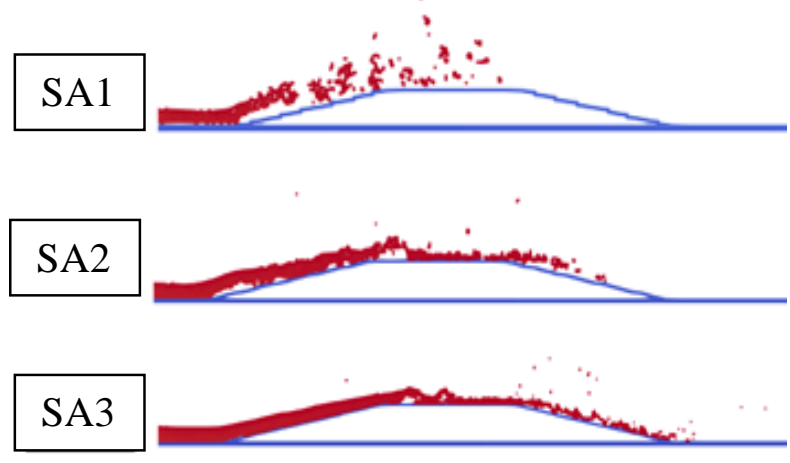

Şekil 5. Eşik üzerindeki parçacık saçılımı

Trapez eşik üzerindeki P5-P8 noktalarında ise $\mathrm{t}\left(\mathrm{g} / \mathrm{h}_{\mathrm{o}}\right)^{1 / 2}=6-7$ boyutsuz zaman değeri civarında, baraj yıkılması dalga önünün trapez eşik başlangıç noktasına ulaşması ile meydana gelen ve gerçekçi olmayan parçacık saçılımı (Şekil 5) sonucu oluşan su derinliği değerlerindeki ani yükselmeler dikkat çekmektedir. $\mathrm{Bu}$ saçılımın çözünürlük ile ters orantılı olarak şiddetlendiği görülmektedir. Bu etki su derinliği değerlerinde bir miktar sapmalara neden olsa da, akım kararlılığının artması sonucu elde edilen homojen parçacık dağılımı ile sonuçlardaki tutarlılık da artmıştır. Bu ölçüm noktalarında, her üç analiz sonucu arasında belirgin farklar oluşmazken, su seviyesindeki kabarma etkisinin azalması akabinde meydana gelen su seviyesindeki düşüşün, yüksek çözünürlüklü analizde daha yüksek doğrulukta yeniden üretildiği görülmektedir.

Nümerik analizler Intel Core i7-8750H CPU, 16 GB RAM ve NVIDIA GeForce GTX 1050 Ti GPU barındıran bir bilgisayar kullanılarak, GPU üzerinden gerçekleştirilmiştir. Üç farklı nümerik analize ait bazı istatistiksel veriler Tablo 2'de sunulmuştur. Parçacıklar arasındaki başlangıç mesafesinin yarıya düşürülmesi ile iki boyutlu bir analiz için beklendiği üzere parçacık sayısında dört kat artış gözlemlenmiştir. Buna karşın analiz sürelerinde 5-6 kat civarlarında artışlar yaşanmıştır. En düşük ve en yüksek çözünürlükteki analizler olan SA1 ve SA3 arasında parçacık sayı bakımından 16 kat fark bulunsa da, zamansal maliyetler bakımında 30 kata yakın farklar oluştuğu görülmektedir.

\section{Sonuçlar}

$\mathrm{Bu}$ çalışmada mansap kısmında trapez kesitli bir eşik bulunan baraj yıkılması akımının nümerik modellemesi EPH metodu kullanılarak gerçekleştirilmiştir. Üç farklı parçacık çözünürlüğü değeri için tekrarlanan analizlerden elde edilen sonuçlar Kocaman [19] tarafindan elde edilen deneysel ölçüm verileri ile karşıllaştırılmıştır ve karşılaştırma sonuçları, çeşitli noktalardaki boyutsuz su derinliklerinin zamana göre değişimleri üzerinden sunulmuştur.

Baraj yıkılması akımın başlangıç evrelerinde, parçacık çözünürlükleri bakımından nümerik analizlerde belirgin farklılaşmalar gözlemlenmezken, hem üç farklı nümerik analiz sonuçları arasında hem de bu sonuçlar ile deneysel ölçüm verileri arasında yüksek dereceli uyumun yakalandığı görülmüştür. Ancak, eşik öncesinde gerçekleşen kabarma sonucu oluşan hidrolik sıçrama ve akabindeki negatif dalga yayılması ile akımın karmaşık yapısından dolayı çözünürlüklere bağlı olarak sonuçlar arasında bariz farklılıkların oluştuğu gözlemlenmiştir. Çözünürlük değerleri ile doğru orantılı olarak dalga yayılma hızı ve dalga boyu değerlerinde azalmalar meydana gelerek, yine çözünürlük değerleri ile doğru orantılı olacak şekilde deneysel ölçümler ile uyumun arttığı karşılaştırma sonuçları ile ortaya çıkmaktadır.

Nümerik analizlerin, çözüm alanının tanımlanmasında kullanılan elemanların sayısının artması ile daha yüksek doğruluklara çıktığının bilinmesinin yanı sıra, yapay viskozite değerinin çözünürlük ile olan ilişkisinin sonuçlar arasındaki farklılaşmanın temel nedeni olduğu düşünülmektedir. Problemdeki yapay viskozite etkisinin arttırılması ile daha fazla enerji dağılımının sağlanacağı ve bununda gerek dalga önü yayılma hızı gerekse dalga büyüklüğü değerlerinde düşüşe neden olacağı ileri sürülebilir. Bununla ilişkili olarak ileriki çalışmalarda farklı parçacık çözünürlükleri ile farkı yapay viskozite değerlinin kullanımının araştırılması, bu etkinin daha iyi anlaşılması bakamından fayda sağlayacaktır.

Ayrıca üç farklı parçacık çözünürlüğü değeri için analizlerin zamansal maliyetleri incelendiğinde, zamansal maliyetlerin parçacık sayısı ile doğru orantılı artmadığ gözlemlenmiştir. En düşük parçacık çözünürlüğü ile en yüksek çözünürlük arasında parçacık sayısı olarak 16 kat artış olsa da, zamansal maliyetler bakımından bu değerin 30 kata yaklaştığı görülmektedir.

Tablo 2. Üç farklı nümerik analize ait parçacık sayıları ve çözüm süreleri

\begin{tabular}{lccc}
\hline Sayısal Analiz No & SA1 & SA2 & SA3 \\
\hline Parçacıklar arasında başlangıç mesafesi (mm) & 5 & 2.5 & 1.25 \\
Toplam parçacık sayısı & 46500 & 186000 & 744000 \\
Toplam analiz süresi (s) & 952 & 4839 & 27984 \\
\hline
\end{tabular}


Sonuç olarak EPH metodunun mansap kısmında bir engel bulunan baraj yıkılması akımının karmaşık dinamiğini makul doğrulukta modelleyebildiği görülmektedir. Ancak EPH yönteminin parçacık çözünürlüğü ve yapay viskozite teriminin yanı sıra diğer belirlenen parametrelere hassasiyetinin detaylı bir şekilde irdelenmesinin yüksek önem arz ettiği ve bu parametrelerin elde edilecek sonuçlar üzerinde dramatik farklılıklara neden olabileceği gerçeğinin göz önünde bulundurulması gerekmektedir.

\section{Teşekkür}

Yazar çalışmanın hazırlanması esnasında yaptığı yardımlarından dolayı Arş. Gör. Ada Yılmaz'a teşekkür etmektedir.

\section{Çıkar çatışması}

Yazarlar çıkar çatışması olmadığını beyan etmektedir.

\section{Benzerlik oranı (iThenticate): $\% 10$}

\section{Kaynaklar}

[1] F. Aureli, A. Maranzoni, P. Mignosa, and C. Ziveri, Dam-break flows: Acquisition of experimental data through an imaging technique and 2D numerical modeling. J. Hydraul. Eng., 134(8), 1089-1101, 2008. https://doi.org/10.1061/(ASCE)07339429(2008)134:8( 1089)

[2] S. Kocaman, and H. Ozmen-Cagatay, The effect of lateral channel contraction on dam break flows: Laboratory experiment. J. Hydrol., 432-433, 145-153, 2012. https://doi.org/10.1016/j.jhydrol.2012.02.035

[3] H. Ozmen-Cagatay, S. Kocaman, and H. Guzel, Investigation of dam-break flood waves in a dry channel with a hump. J. Hydro-Environment Res., 8(3), 304-315, 2014. https://doi.org/10.1016/j.jher.2014. 01.005

[4] H. Ozmen-Cagatay, and S. Kocaman, Dam-break flow in the presence of obstacle: Experiment and CFD simulation. Eng. Appl. Comput. Fluid Mech., 5(4), 541/552, 2011. https://doi.org/10.1080/19942060. 2011.11015393.

[5] H. Ozmen-Cagatay, and S. Kocaman, Investigation of dam-break flow over abruptly contracting channel with trapezoidal-shaped lateral obstacles. J. Fluids Eng. Trans.ASME,134(8), 2012. https://doi.org/10.1115/ 201.4007154.

[6] S. Soares-Frazão, and Y. Zech, Experimental study of dam-break flow against an isolated obstacle. J. Hydraul. Res., 45, 27-36, 2007. https://doi.org/10. 1080/00221686.2007.9521830.

[7] M. İlkentapar, and A. Öner, Geniş başlıklı savak etrafındaki akımın incelenmesi. Niğde Ömer Halisdemir Üniversitesi Mühendislik Bilim. Derg., 6, 615-626, 2017.

[8] M. Aydın, and C. Kaplan, Ilısu barajı dolusavak havalandırıcısı performans analizi. Niğde Ömer Halisdemir Üniversitesi Mühendislik Bilim. Derg., 8, 902-911, 2019. https://doi.org/10.28948/ngumuh. 598248

[9] A. Issakhov, Y. Zhandaulet, and A. Nogaeva, Numerical simulation of dam break flow for various forms of the obstacle by VOF method. Int. J. Multiph.
Flow, 109, 191-206, 2018. https://doi.org/10.1016/ j.ijmultiphaseflow.2018.08.003

[10] S. Kocaman, and H. Ozmen-Cagatay, Investigation of dam-break induced shock waves impact on a vertical wall. J. Hydrol., 525, 1-12, 2015. https://doi.org/ 10.1016/j.jhydrol.2015.03.040

[11] H. Ozmen-Cagatay, and S. Kocaman, Dam-break flows during initial stage using SWE and RANS approaches. J. Hydraul. Res., 48(5), 603-611, 2010. https://doi.org/ $10.1080 / 00221686.2010 .507342$

[12] A. Yilmaz, K. Dal, M. Demirci, and S. Kocaman, Numerical investigation of dam-break flowovera bottom obstacle using eulerian finite element method. Int. J. Adv. Eng. Res. Sci., 4(12), 203-208, 2017. https://doi.org/10.22161/ijaers.4.12.30

[13] R. Gingold, and J. J. Monaghan, Smoothed particle hydrodynamics: theory and application to nonspherical stars. Mon. Not. R. Astron. Soc., 181, 375189, 1977. https://doi.org/10.1007/s00769-003-0757-y

[14] L. B. Lucy, A numerical approach to the testing of the fission hypothesis. Astron. J., 82(12),1013-1024, 1977.

[15] A. J. C. Crespo, M. Gómez-Gesteira, and R. A. Dalrymple, Modeling dam break behavior over a wet bed by a SPH technique. J. Waterw. Port, Coast. Ocean Eng., 134(6), 313-320, 2008. https://doi.org/10.1061/ (asce)0733950x(2008)134:6(313)

[16] K. Dal, S. Evangelista, A. Yilmaz, and S. Kocaman, Validation of dam-break problem over dry bed using SPH, Int. J. Adv. Eng. Res. Sci., 4(12), 209-213, 2017. https://doi.org/10.22161/ijaers.4.12.31

[17] R. A. Dalrymple, and B. D. Rogers, Numerical modeling of water waves with the SPH method. Coast. Eng., 53(2-3), 141-7, 2006. https://doi.org/10.1016/ j.coastaleng.2005.10.004

[18] M. Gomez-Gesteira, and R. Dalrymple, Using a threedimensional smoothed particle hydrodynamics method for wave impact on a tall structure. J. Waterw. Port, Coastal, Ocean Eng., 130(2), 63-69, 2004.

[19] S. Kocaman, Baraj yıkılması probleminin deneysel ve teorik olarak incelenmesi. Çukurova Üniversitesi Fen Bilimleri Enstitüsü, Adana, 2007.

[20] A. J. C. Crespo, DualSPHysics: Open-source parallel CFD solver based on smoothed particle hydrodynamics (SPH). Comput. Phys. Commun., 187, 204-216, 2015. https://doi.org/10.1016/j.cpc.2014.10.004

[21] H. Wendland, Piecewise polynomial, positive definite and compactly supported radial functions of minimal degree. Adv. Comput. Math., 4, 389-396, 1995.

[22] J. J. Monaghan, Smoothed particle hydrodynamics, Annu. Rev. Astron. Astrophys., 30, 543-574, 1992.

[23] G. K. Batchelor, An introduction to fluid mechanics. UK: Cambridge University Press, 1974.

[24] A. J. C. Crespo, M. Gomez-Gesteira, and R. A. Dalrymple, Boundary conditions generated by dynamic particles in SPH methods. Comput. Mater. Contin., 5(3), 173-184, 2007.

[25] B. J. Leimkuhler, S. Reich, and R. D. Skeel, Integration methods for molecular dynamics, in mathematical approaches to biomolecular stru1cture and dynamics. Springer., New York, 185. 